\title{
VIOLENCE, JUSTICE, AND ALIENATION IN EDWARD BOND'S PLAY
}

SAVED

\author{
Asaad Alabody ${ }^{1}$, Mohsen Hanif ${ }^{2}$ \\ ${ }^{1} \mathrm{PhD}$ candidate Department of Foreign Languages, ${ }^{2}$ Assistant Professor, Kharazmi University, Tehran, Iran. \\ Email: assad_alabody2000@yahoo.com,mohsen.hanif@gmail.com
}

Article History: Received on $12^{\text {th }}$ July 2019, Revised on $30^{\text {th }}$ August 2019, Published on $23^{\text {rd }}$ September 2019

\begin{abstract}
Purpose: The current study tries to explore the concept of violence; Justice and alienation in Edward Bond's play Saved. Saved is one of his plays to address the problem of social justice, violence and alienation in the modern world. It also seeks to show the causes which lead to violence and injustice in society. Then it goes to analyze the symbiotic relationship between the human imagination and reason in creating ideologies that affect the society and produce alienation, justice and violence.
\end{abstract}

Methodology: Violence, justice and alienation are prominent phenomena enormously discussed today. Many thinkers have tried to talk about these concepts, but this research has dealt with examining these concepts in the thought of Edward Bond. In this context, data have been collected by using library and documentary method. First, violence, justice and alienation are discussed. Bond a social theorist discusses that a healthy man is a man that connects with the world by love rather than violence, but the aliened man turns toward domination, submission, destruction or combination. Bond discusses that the root of alienation, justice and violence are found in capitalist society and are released through socially.

Results: Bond's life has witnessed the events of the Second World War and he has seen the destruction of the cities and the suffering of the people. He is highly aware of the miserable situation in which people lived. He could agitate the audience against the government by the violence shown in his plays. Bond deals with investigating the characteristics of a healthy society. Regarding the approach, he discussed that people having not the desired characteristics will be considered as aliened men. The man who does not have health symptoms would be alienated.

Implications: Since people engage in the inauthentic world, subjugated to oppression, live in the misery of universe, succumb to the disasters of everyday life and lack of rights, Playwrights can show and expose in their plays the suffering and suppression that individuals are subjected to. Writers and thinkers can guide people to authentic life and obvious truth of being through their lucid and objective language.

Keywords: Alienation, Ideology, Inhumanity, Justice, Violence, Edward Bond's play 'Saved'.

\section{INTRODUCTION}

Literature is not merely means of gratification, pleasure, and eloquence but they also depict the conditions of the societies. An essential element in helping to evaluate the value and status of Bond's writing over the past half-century is the wider international context in which both his earlier major works and more recent plays are produced. From the early to mid1990s especially, his plays have received an ample critical reception in France. His plays have also been successfully formed in Germany, Italy and more recently Canada. In addition to his major role as a dramatist, he is a cultural and national theoretician, essayist and poet too. His career dates back to the first proficient performance of his play The Pope's Wedding (1962). Since then his work has been considered by a rigorously rational, materialist view of humanness, society and culture (Billingham, 2014).

Edward Bond was born into a world of destruction and alienation and experienced the traumas of both evacuation and London and Europe shocked by the indiscriminate bombing of civilians and the innocent. This terrifying world characterized by violence and misery was also perhaps actually reinforced by his experience of national service and the suppressive regime of institutionalized army life. It is possible that Bond's experience of a war-ravaged childhood and post-war and alienation left a cruel and indelible mark upon him and a deep wound can't be healed (Billingham, 2014).

The cultural notions of society are a key concern in the works of the contemporary British playwright, Edward Bond. He mentions in the summary to his play The Fool: Scenes of Bread and Love, published in his third volume of plays "Culture is the rational creation of human nature ... Art helps to monitor the creation of culture and reflects the past and future in the present" (Bond, 1987). The idea that deals with Bond's definition of culture is the most significant definition of human imagination. Human beings have to realize the world and their place in it.

Edward Bond is highly concerned with events that help understand the obligation of his plays to human values. Bond seems to involve in theatre to shed a light on the position of the writer, of the creator of art in society. His consciousness of belonging to a particular class and social structure delivers the special "flavour and character" of his plays. This violent events and consequences which shared by many other children of his generation help him to create an acute sensitivity. The evacuation leads him to realize a lot of things and this realization seems to be common to other children who lived the same drama turned Bond into a playwright who was able to succeed in showing his mastermind, his talent with the clarity of vision of a child. 
Bond has felt disappointed with the institutions of contemporary British theatre and this disappointment reveals his commitment to the theatre as an agent of social change. In rejecting the Royal National Theatre a license to display his play Saved in 1999, he claims that this theatre "trivializes drama" and hence does not accomplish its social obligation to challenge the problems of being human (Bond, 2014). At several times in current years Bond(2014) has worked with the two main theatres that supported him in the UK, the Royal National Theatre and The Royal Shakespeare Company, and has reached to the idea that they have been involved with finding what "works" in practice than involving in analysis of the plays' political uses. The result is a theatre which he thinks is concerning with frivolity, entertainment and commercialism than with social realities or political radicalism (P.2).

Bond's thought that theatre has a strong social, cultural, political and moral aim has made him write plays for educational contexts, where it is broadly believed that drama is an essential practice which, in his words, "enables us to understand ourselves and what we do" (Bond, 2014). For Bond, the Theatre in Education movement tries to convey fundamental values about theatre in general. He is interested in the drama which not only summonses young people to question the world around them but also inspires them to conceive how it could be different.

Throughout his career, Bond has frequently contemplated the nature, roots, and function of violence in society. One of the most important and unforgettable images and events in post-war British theatre and twentieth-century theatre as a whole is realized in his play, Saved (1965), in the stoning to death of a baby in a pram in a public park by a group of idiot men. This has predictably stunned contemporary reviewers and audiences. For Bond, violence is always principally an outcome and sign of corrupt and exploitative social organizations. So, within the ridiculous site of the park in Saved, the violence can be viewed and analyzed from multiple viewpoints. On one level it is a violently premeditated demonstration of socially gendered codes of masculinity-as-violence. Simultaneously, this public demonstration of violence also states and reflects the policy of state-sanctioned violence. Bond claims that the stoning to death of a baby in a London park is an English understatement. Compared to the deliberate bombing of German towns it is an unimportant atrocity, compared to the national and emotional deprivation of most of our children its concerns are negligible. For Bond, violence can always have specific material and ideological state. This violence is frequently sanctioned by the monarchy or the state as a means and expression of power and control, and the resistance can be crushed to the political hierarchy. Bond has made lots of achievements as a dramatist. Bond fights and challenges the nature of totalitarian power enforced by state-authorized violence. Our society is shaped and obsessed with violence and this violence should be stopped because if we do not stop it, we will have no future. Bond says people who want writers to stop writing about violence; they want to deter society from fulfilling its goals. A society that looks for the freedom of expression and equality in allocating rights to people. Bond has revolted against the tyranny and suppression which has been used and imposed on the working class. The working class is suppressed and humiliated by the successive governments. Such a class was described as an alienated class from society (Billingham, 2014).

\section{THE ANALYSIS AND DISCUSSION}

However, Bond's play, Saved challenged openly and stood forcibly against oppression and capitalism. It highly defended society and fought for its right. It also antagonized the powers of censorship which were imposed by the Lord Chamberlain's office.

Saved investigates the lives of the oppressed working class youths by a cruel economic and social system which are not able to give their lives meaning and lead society to plunge into brutal violence. Among them, one character, Len, actually tries to keep links between people cruelly ripping each other to pieces. The play will explain the social reasons for violence and confronts them with personal freedom. This can be described as the main theme at Bond's work. Since Bond has been evacuated during world war11 and this evacuation leads him to expose the violence and horror of war which forms themes in his work. Bond is entirely aware of social alienation that the society suffers from and such an idea will be characterized by his writing. This research goes deeply to assess the use of extreme violence in Edward's Bond play as opposed to his main consideration with peace and optimism in the temporary capitalist society. Bond's strong points and ideas relating people's interests, religion and human relations are marked in the themes of his controversial plays. Bond presents important details to show the overpowering violence, absurdity, an allegory of his plays, and to sketch his belief that the intrinsic function of the theatre is to make a social change. As Bond thinks that the theatre role should be activated to challenge social problems.

Bond thinks the theatre is a suitable way to overcome the serious problems of society and paves the way to spread intellectual thoughts among people. Violence impacts upon the rights and lives of the individuals in different ways; it becomes the main theme in modern literature. States still live in different kinds of inconsistencies. Some great powers raise the slogans of peace, justice, and harmony but at the same time, there is suppression of the weak nations which imposed by Great powers. These states have contradicted themselves nuclear ban treaties have been imposed only on the developing countries while Great powers have granted legislation to possess, import and export all weapons. This can be indicated as the essence of modern civilization. Bond's play deals with the capitalist society in the mid of the twentieth century. Capitalism can be described as an economic system and it is classified as one of the aggressive systems of human history. It is the mainstream of violence and alienation. Society has been bifurcated by capitalism into separate groups of the possessed and the dispossessed. Bond sheds light on socio-political problems are prevalent in a capitalist society. 
In a system of inequalities, prejudices, cruelty, and self-regard become the most vivid ways of behaviour. Violence can be defined as a physical force used to hurt, destroy, or kill someone or something while alienation can be defined as an activity or practice of being secluded from a society to which one should be in or in which one should be included (Wagar,2015).

However, the play attempts to explore the dehumanizing industrial situation, the moral emptiness of the working-class world of South London and the rudeness and cruelty that have resulted. The play is about a girl, Pam, who is from the beginning flirts with a young man, Len, and indifferently has a love affair with him. Pam shortly goes to have a new lover, Fred but Len's obstinacy does not allow him to leave Pam's parents' home. Len does not change and always remain loyal to Pam in spite of her giving birth to Fred's undesirable child. The situation begins to get worse and the problems arise and result in the open quarrelling between Len and Pam, or between Pam and Fred. The atmosphere keeps on fighting in restless silence between Pam's father and mother ( $\underline{\text { Scharine, 1976)}}$.

Len decides to go away but in the penultimate scene, Harry, pitiful in his long isolation and seclusion, persuade Len from going. In the last scene, all the family members seem to attend together in the living-room: The chair which has already been broken in a previous quarrel, Len appears fixing it, Mary is cleaning the table, Harry is filling out his football betting slip, and Pam is having a seat on the couch and reading her magazine $(\mathrm{P}, 42)$.

The discord, pointlessness and lack of familial relationships and affection are obvious from the beginning of the play when a young girl, Pam, whose life should have a clear aim, creative, and optimistic, brings a stranger, Len, to her house just to fill her sexual desire. The two seem to be not known even their names because when Len asks Pam about her name she responses "Don't be nosey"(Bond 1977). Bond's purpose is an attempt to present a realistic portrayal of a lifestyle which is completely controlled by certain social conditions (Scharine,1976).

Despite Pam's father staying at home, she keeps on using the living-room because her "Bed ain' made"(1977). Pam tells Len that she does not live alone when he asks her "Live on yer tod?" (P, 11). Thus, Len looks self-conscious to see Harry, Pam's father, going back and forth of the living-room. Inconsistently, Pam appears that she does not care for her father's presence. This can be seen clearly in the following dialogue between Len and Pam:

\author{
LEN. I thought yer reckon yer was on yer tod? \\ PAM. 'E's late for work. \\ LEN. O. Why? \\ PAM. Why? \\ LEN. Yeh. \\ PAM. I don't know. \\ LEN. Reckon 'e saw? \\ PAM. shouldn't be surprised. \\ LEN. Will ' e be long? \\ PAM. Don't arst me. (P, 13-14)
}

Moreover, Scharine (1976) says that the father, from his side, does not say any word with his daughter as he gets ready to go to his night work-shift. This boredom and lack of interaction between the father and his daughter seems to be reflected and even strengthened by the same unfruitful connection between Harry, the husband, and his wife, Mary. Anyway, Harry's going out to work and Mary's coming back home foretells their misunderstanding, lack of familial relationship, and inconsistent life.

Later on, some filthy jokes have happened between Len and Pam. This kind of joking can be described as a way of satirizing all the institutions of the time whether cultural, social, or political. Hence, the culture of the characters in the play is grounded on scorn for life; therefore, their view of sex is obscene and their association with one another is hostile.

Both children and women are subject to abuse in Saved because they do not have respectable status in that brutal, hostile society in which they lived. For example, the boys' mocking of Mary when Len goes to her in the third scene is violent and humiliating:

PETE. One man's meat.

MIKE. More like scrag-end.

BARRY. Bit past it, ain' she?

PETE. She's still got the regulation 'oles.

MIKE. Experience 'lps. Yer get a surprise sometimes. (P, 32)

In fact, Mary feels frustrated and suffers from the lack of affection, love and any marital relationship with her husband, Harry. Harry's behaviour makes her disheartened and leads her physically approach her daughter's ex-boyfriend, Len in the ninth scene. Mary seems to be comfortable and allows Len to feel free to bring women into his room. To flirt, Len, Mary tears her stocking near the top and asks Len to sew while she still has it on. As he is sewing it, Harry comes in but he does not matter to them, and then leaves. Mary's seductive scene with Len can be compared the opening scene of her daughter to Len. This portrayal of relationship can show us the unpleasant relationship between Harry and Mary has been repeated by the new generation; Len and Pam (Trussler, 1976). 
Remarkably, all the characters in Saved suffer alienation from the natural world, from each other, from society, and their work as a whole; the result is extreme isolation. However Bond does not urge the audience to sympathize with the characters because once you have sympathy for somebody, you attempt to create excuses for him. This means that you justify the mistake and then accept who has made it. Inconsistently, Bond instigates his audience and awakens them to react by taking action and recognizing and tackling the socio-political defects in their life. Bond asserts the audience should not show sympathy for the characters that trapped in certain desperate situations. Hence, the audience is shown things which, individually and cumulatively, are nerve-racking and the audience should include themselves to reach the causes (Hay, 1980).

Fromm (1961) in his book Marx's Concepts of Man describes the activity and productivity of the man can't be achieved in the objective world freely. The individual is restricted to achieve self-realization through creativity. The specified nature of work deters the worker a sense of freedom. The culture of production and manufacture disrupts an individual's activity and creativity in his world. He defines the modern experience of alienation for the man in the following words: "Alienation (or estrangement) means for Marx, that man does not experience himself as the acting agent in his grasp of the world, but that the world (nature, others and he himself) remain salient to him. They stand above and against him as objects "(P.44).

As Bond grows up in a country has been devastated by wars, so he is forced to be aware of the potential for violence and disruption from an early time. Air raids make him feel disturbed to see the shrapnel in the streets and feeling sorry to observe the rubble of the destroyed houses in which he has once been. Such kind of violent activities leads him to react when an explosion in a park stripped the streets bare of leaves. This is the reason which makes Bond write the baby's killing in Saved. There was always the possibility that violence could explode in a society who lived under severe conditions and social alienation. Bond demonstrates that he is aware of human evil and this awareness is slightly derived from his knowledge of Hitler: He was a human being, but he was behaving in a way which was inhuman, ridiculous. It generated in one's world an image of total evil; you see which was very curious because it wasn't explained by anything which one had experienced before (Demling, 1983). Bond has become a man of consequences rather than solutions. His attempts to overcome violence remain as lucid as ever. Bond as being deals with humanitarian issues rather than political issues. His main concern is to find instant solutions to the problems and suffering of society (Stuart, 1991). Saved sets in South London and shows the effects of an act of violence on ordinary people. The act of violence can be presented by the murder of an innocent baby by rude men, which is displayed properly and staged troublingly. In the interview, Bond (1966) spoke volubly to Gordon:

I sometimes find violence on the stage much more horrifying than violence in actuality. You can see two drunken men fighting on, say, a Tube platform when you get out of a train late at night and you walk past with your head averted. But when you see the same thing on the stage it seems far, far worse; partly because the play has been leading up to it and you are in a sense anticipating it; partly because you are a captive audience. Anyway, the violence comes over as being more shocking. Bond could do. I expect it depends on how successful the dramatist is at portraying the violence. (P.8)

The violence in Saved has a certain amount of publicity and such publicity can be used as a motivation to society to revolt against the suppression and injustice. Bond always regards the theatre is an essential way to defend people and creates and provides solutions. Bond institutes the distinguishing features of a new theatre that stands against capitalism in all its forms. He does his best on a new stage vision that illustrates cruelty and humiliation of contemporary life. As a playwright, he strictly adheres to humanistic values; he boldly likes protesting against social and political injustice. Bond confirms that the theatre is a way of organizing society and helping to change it; art should go deep and interpret the world and not merely look at it(Letters volume1, P.34). Bond defends society strongly and he tries to urge the states to do justice to the society. According to Bond's understanding, Justice can be a verified concept. It is important to draw a distinction between the laws, legal, justice, law, and order. All members of society should obey these rules. These rules are made by the legislature, administered by courts and enforced by army and police. Social justice is more significant than the law. Social justice includes politics, culture, and customs. It allows people to live freely.

Everybody has different abilities and needs. Social justice does justice to everybody and tries to fulfil their different potentials. Everybody can be treated equally before the law, but everybody is unequal before social justice. It is also important to divide social justice into the community and society. By community, it means the relationships between people which allow them to follow their aim humanely. The community is based on trust, friendship and sharing a common life. By society, it focuses on the economic and organizational structure into which all should be fitted. The economy allows the individual to make, buy and sell. In a community, the poor and rich may be equally glad and kind within their means. These human qualities can't be held in economic society. The economy is not a human structure; it is not determined by human virtues. It has life and logic of its own. Our economy is recognized after its driving force capitalism. In the end, it can serve justice, but following the economy's laws is not the same as following the laws of justice.

There is an important factor should be added as a means of assistance to the economy. It is power. Money can be considered as the power that makes our economy work. Power is money. The more money you have the more power you get (Bond, 2013). 
Concerning the cultural system of society, the human imagination and reason are a major purpose to create ideologies in defining culture and its impacts on society. According to Bond's view, culture, and society are the elements of human behaviour. Individuals are different from animals since they are awarded a fertile imagination. Human beings are free to be creative or destructive. Imagination aim is to form the fiction that depicts the world and our self and makes it understandable to all. In the Notes on Imagination published in his seventh volume of plays, Bond (2003) says "Imagination and reason are closely symbiotic. The story which is imagination's structure is acquired through reason, through description, explanation and evaluation ...It is an article of faith to the ideology that we are creatures of instinct. But really when we behave like animals we do so specifically because we are not animals"(P.107)

Bond contends that imagination is supposed to inform the principle of reality and fiction for human beings, and directs them to realize themselves and the world in which they live. Therefore Bond's definition of culture represents this feature of human instinct, that is, the imagination as an effective power that forms it.

The following important notion in this regard is one, which is carefully connected with the human imagination, namely ideology. In Bond's introduction to his seventh volume of plays, titled The Cap: Notes on Drama, the Self and society, Bond confirms that culture should be a basic source of meanings of the world, which understands that it is itself part of that meaning. Bond's view, ideology is the notion of "Nothingness" which can create the world and make our selfunderstandable to us (Bond, 2003).

Bond's works are contributed to constructing awareness about the lack of self-understanding in humans as a species, corrupting the human imagination and forming complicated ideologies. He writes in the introduction to his seventh volume of plays that there are three negative solutions to this lack of self-understanding, that is, violence, transcendentalism and somnambulism. He presents transcendentalism as the meaning given to them self concerning the world, which is a kind of insanity that makes the insane incapable of social living or allows the sane to live in an unjust society. Somnambulism is the attitude that culture evolves without any vision into the future or relation to the past (P. X-Xii).

However, Bond admits being philosophical, which displays that his intention is not to cast light on hardships but also to form consciousness about the philosophical ideas that seek to form a specific culture. Bond (1998) says in the Commentary on the War Plays, published in his sixth volume of plays that "The human mind's strength is that it is not determined by instincts but generates culture; its weakness is not that we inherit animality but that we inherit history and the culture of the past" (P.253).

An article titled Violence - A Recurrent Theme in Edward Bond's Plays Imagery and Symbols, Manoliu (2014) says that Bond's themes can simply be seen in his approaches to art, culture and society, which he traces as being closely associated with deep roots in violence, religion, morality and reality as a reason of political and personal tragedy, the lack of integration between the reality inside an individual and the social reality, the individual's relationship with his family and society are repeated themes in Edward Bond's plays(P.364).

It is noticeable that the theme of violence is developed in Bond's plays and it could also be seen from a different standpoint: taking account of the pair's victim and victimizer, aggressor and the one who suffers the aggression. Bond's plays have similar characters and you might see the same character in various stages of development. Len's character who seems to be clear in Early Morning is the same as Len who appears in Saved and the trial in the play Saved is that from the first act of Early Morning seen through Arthur's eyes. Len in Early Morning focuses on the personality between himself and Len/Arthur in Saved: by hitting the dead man's clothes that they refer to in most of Bond's plays where we can realize those aggressors are also victims of the society. So this idea is crystallized in their mind that they put on the dead man's clothes. The unified issue between the victim and the victimizer, the aggressor, this contrast between characters is very significant for the idea and message of each play. The hero is always presented with a counterpart: Scoopey-Allen; LenFred; the Twins and thus the struggle between these individuals are already stable. They all are fascinated and disproved by one another and they all include each other in death.

One of Bond's features on stage is to show a kind of theatre counterpoint where two actions are juxtaposed, occasionally in ironic contrast, usually to broaden and clarify the individual actions. Thus, events are seen as happening in linking with other events and not as self-sufficient inevitable incidents. Bond has a very strong vision and most of the events in his plays in which concerning the organization of people and all the other elements are very evocative. Bond's plays can demonstrate and explain social procedures in action so, his characterization is deep-rooted, especially, in classes and society, the writer is strongly focusing on the actions of human beings in complex circumstances (Manoliu, 2014).

Bond has always confirmed the need to realize and to infer rationally our past to make use of the experiences in our present and not to repeat the errors committed. Some of Bond's works have a contemporary setting, as The Pope's Wedding (1962), the polemical play Saved (1965), and always, over the past thirty years, he has focused on social injustice, violence, individual alienation, and corruption, caused by a class-structured, technocratic society and has pointed to the urgent need to react and to create a better world.

Bond has compared the killing of the baby in Saved to the killing of the baby in Great Peace in the light of developing of society view. The baby-killing in Saved seems to be more effective which causes a huge outrage while the baby-killing in Great Peace has caused no reaction toward it as it was in Saved. It is simply because society is changing. People start to 
realize issues differently and also Bond uses the murder in Great Peace for different aims. According to Bond's view, there's realism about the killing of the baby in Saved, which he thinks shocks people because they sense they could go out in the street and see how things are going on. This can be accounted for as a good reaction. The killing of the baby in Great Peace is done very carefully, with a floor cloth. It seems like giving the baby sweets when they murder it. It's a very calm way, while the killing of the baby in Saved is very fierce (Klein, 1995).

Bond blames the government of not paying enough attention to reintegrating the underprivileged back into society since social programs which should bring reforms are not seriously taken into consideration. This indifference can also create policies for homeless people thinking we understand them well.

Bond mentions in Note on Imagination, in a society where the official decision of politicians is full of lies, and where the authorities turn a blind eye to their criminal acts by finding loopholes in the legal system, it is difficult to combat injustice and violence. Those who are maltreated by indifferent policy usually resort to violence themselves being incapable to deal differently with the situation they are placed in. They are overwhelmed by a social atmosphere in which "the need for justice becomes the desire for revenge" and "the need to create becomes the necessity to destroy"(P. 25). However, revenge can lead us neither justice nor peace. Continuing violence does not offer good results.

In The Hidden Plot, Bond (2014) is against any kind of violence but he feels empathy for people who are dominated by oppressive policies because they are the victims of the system. If the government realized them, they would not be angry and despondent. If a person is always degraded, he or she will lose some parts of their humanity, eventually. The same thing inevitably occurs to those who are degrading them, under numerous conventionally legitimate and socially adequate justifications. Bond proclaims to bring Western democracy to trial. "Western democracy has become a secret Culture of Death. Instead of speaking the human language we chant alchemical spells and arm our magic with the terrors of gigantesque technology" (P.8). Democracy in which injustice, violence and intolerance flourish certainly deadens our humanity. Moreover, persistent military actions of the Western countries in tackling various political issues, certainly excuse authorities to accuse modern culture of being deadly. Bond (2013) says in Note on Imagination, this kind of authority is usually suppressive and aggressive. Besides, this means that apparently for a better society to exist, authorities often use force and violence to carry out their rules. Their ideology truly validates their injustice (P.33).

\section{CONCLUSION}

Writers were disheartened with the corrupted twentieth-century world that was full of injustice, violence, despair, genocide, famine, and loss of communication in everything. This chaotic world needed the writers to agitate the people against the threats they were facing. Thus, many politically oriented literary tendencies appeared that reflected the sorts of miseries the people were undergoing. Bond believes that as long as man is forced to the socio-political institutions, the cycle of violence continues and the perspective remains desperate. The theatre was employed dramatically to agitate the audience against corrupt political systems and social situations. Playwrights came to use theatre as a way to stimulate people to realize the injustices of their society.

The terror of a futureless society is dramatized in Saved, one of Bond's early plays, through the metaphor of child-murder which is considered as one of the nerve-racking scenes performed in modern drama. The hope of society is refuted when a baby recovering from pneumonia is numbed into a comatose state by its mother and stoned to death by a group of idiotic youths including the baby's father.

It seems clear to conclude that Bond struggles to defend the society at the lower class hardly and he assures that his plays should be precisely understood in the process of their rehearsal and production. Bonds confirms that the most important thing is the necessity to achieve what he looks for and concentrating his works to find solutions and principles of equality in a society that has suffered for long decades. Bond says that there is a shared responsibility for us all to consider and bear in mind the critical conditions which should be defeated or solved. I think that Bond has continued to improve and express an illuminating searchlight upon us and our world and our possibility of having a promising future. Edward Bond has an effect offered up a mirror to the times in which he and we live. These requirements for humankind are lost in the classstructured capitalist society against which Edward Bond's view stands.

\section{REFERENCES}

1. Billingham, P. (2014). Edward Bond: A Critical Study. London: Palgrave Macmillan. https://doi.org/10.1057/9781137368010

2. Bond, E., \& Gordon, G. (1966). Edward Bond: An interview by Giles Gordon. The Transatlantic Review, (22), 715 .

3. Bond, E. (2013). Notes on Imagination. Methuen Contemporary Dramatists. London: Methuen London.

4. Bond, E. (1977). Plays One: Saved, Early Morning, The Pope's Wedding. London: Methuen.

5. Bond, E. (2014). The hidden plot: Notes on theatre and the state. A\&C Black.

6. Bond, E. (1987). Plays: Volume 3.8 vols. London: Methuen Publishing Ltd, Print.

7. Bond, E. (1998) Plays Volume 6.8 vols. London: Methuen Publishing Ltd, Print.

8. Bond, E. (2003). Plays: Volume 7.8 vols. London: Methuen Publishing Ltd, Print.

9. Demling, A. M. (1983). The Use of the Grotesque in the Plays of Edward Bond. 
10. Fromm, E. (1966). Marx's concept of man. New York: Ungar.

11. Hay, M., \& Roberts, P. (1980). Bond, a study of his plays. Methuen.

12. Klein, H. (1995). Edward Bond: An Interview. Modern Drama, 38(3), 408415.https://doi.org/10.3138/md.38.3.408

13. Manoliu, M. N. (2014). Violence-a Recurrent Theme in Edward Bond's Plays Imagery and Symbols. International Journal of Communication Research, 4(4), 363.

14. Scharine, Richard (1976). The Plays of Edward Bond. London: Bucknell University Press,

15. Stuart, I. (1991). Answering to the Dead: Edward Bond's 'Jackets', 1989-90. New Theatre Quarterly, 7(26), 171183.https://doi.org/10.1017/S0266464X00005443

16. Stuart, I.(1994). Edward Bond Letters I. 5 vols. Philadelphia: Harwood Academic Publishers. Print.

17. Trussler, S. (1976). Edward Bond (Vol. 249). Published for the British Council by Longman.

18. Waqar, B.(2015). From Realism to Expressionism: The Pope's Wedding, Saved and Early Morning by Edward Bond. 